\title{
Physicochemical and Antioxidant Properties of Kiwifruit as a Function of Cultivar and Fruit Harvested Month
}

\author{
Ramesh Singh Pal ${ }^{*}$, Vandana A Kumar ${ }^{1}$, Sandeep Arora ${ }^{2}$, A K Sharma ${ }^{3}$, Virendra Kumar ${ }^{4}$ \\ and Sanjeev Agrawal ${ }^{1}$ \\ ${ }^{1}$ Department of Biochemistry; College of Basic Science and Humanities; Govind Ballabh Pant University of \\ Agriculture and Technology; Pantnagar - Uttarakhand - India. ${ }^{2}$ Department of Molecular Biology and Genetic \\ Engineering, CBSH, GBPUA \&T; Pantnagar - Uttarakhand - India. ${ }^{3}$ Department of Biological Science; CBSH, \\ GBPUA \&T, Pantnagar - Uttarakhand - India. ${ }^{4}$ Department of Chemistry; CBSH, GBPUA \&T, Pantnagar - \\ Uttarakhand - India.
}

\begin{abstract}
The present study was carried out to find the effect of fruit harvesting stage (October, November and December) on the physicochemical and antioxidant properties in five kiwi cultivars (Abbot, Bruno, Allison, Hayward, Monty). Results showed that soluble solid content (SSC) and pH increased while ascorbic acid (Vit C), titrated acidity (TAD) and SSC/TAD decreased in all the cultivars with delay in harvesting. Total polyphenols (TP) were decreased while total flavonoids (TF) increased in all tested cultivars with delay in harvesting. The highest concentration of TP (2.02 $\mathrm{mg}$ gallic acid equivalent/g fresh weight) and TF (51.12 mg catechin equivalent/100 $\mathrm{FW}$ ) were found in cultivar 'Allison' in the month of October and December, respectively. Antioxidant activities (AA) were genotype depended and no trend was observed with month of harvesting. Principal component analysis (PCA) showed strong correlation between Vit $C, T P$ and antioxidant activities. Two major clusters were computed using agglomerative hierarchical clustering $(A H C)$. All the studied important traits may be used in the breeding programmes to increase the variability for different physiochemical and antioxidative characteristics and to make suitable selections that could be acceptable to consumers.
\end{abstract}

Key words: Antioxidant Properties, Kiwi Fruit, Fruit Harvest Month, Physicochemical Properties

\section{INTRODUCTION}

Actinidia chinensis L., (syn. A. deliciosa) is a commercial crop in New Zealand and other countries such as Chile, China and Italy (Ferguson and Huang 2007; Nishiyama 2007). In India, the area under this fruit is very less, due to its exotic introduction. With extensive research and developmental support, its commercial cultivation in India has been extended to the mid-hills of Himachal Pradesh, Jammu-Kashmir and Arunachal Pradesh. Kiwifruits are normally consumed as fresh fruit, because fresh peel of fruit is having a wide range of compounds leading to distinct flavors in the fruit (Atkinson and Macrae 2007). The appearance and nutritional values are generally influenced by the pigments and vitamins present in the fruit where- as taste is primarily influenced by the acidity, sweetness and volatiles. Two common ways to quantify the acid content of the samples include the determination of initial $\mathrm{pH}$ and titratable acidity (TAD). The magnitude of $\mathrm{pH}$ provides immediate or actual acidity (actual hydrogen ion concentration). Titratable acidity indicates the total or potential acidity such that it includes the total number of acid molecules.

*Author for correspondence: ramesh_bio2006@ rediffmail.com 
Soluble solids content (SSC) includes molecules that are truly soluble in an aqueous sample. In commercial standards, the SSC of a ripe fruit is often used to indicate its sweetness (Crisosto and Crisosto 2001). SSC is measured as the units of Brix value that is defined as percent sucrose by weight. SSC has been shown to reflect the eating quality of ripe fruit. The ratio of sugar to organic acids (SSC/TAD) has been related to flavor quality for a variety of fruit and indicate the optimum time for harvesting (Burdon et al. 2004).

Healthful attributes of kiwifruit are high ascorbic acid levels (Ferguson and Huang 2007), polyphenols (Sheng et al. 2005), and the presence of flavonoids (Atkinson and Macrae 2007). Kiwifruits are used for the treatment of many different types of cancers, e.g., stomach, lung, and liver cancer (Yang 1981) in traditional medicine. Some studies have shown that the extracts of kiwi fruits inhibit cancer cell growth (Song 1984) and exhibit cell protection against oxidative DNA damage in vitro (Collins et al. 2001).

Antioxidants have become a popular research topic because they can not be generated by the human body and hence have to be consumed in the diet. They may be defined as any substance that when present at low concentrations significantly delays or prevents the oxidation of that substrate in a chain reaction (Halliwell and Whiteman 2004). Many fruit and vegetables are rich sources of antioxidants. Kiwi fruit has been well described for its composition. A lot of work has been done on the biological activities of kiwi fruit but very little information is currently available about the antioxidant activity of this fruit at different harvesting stage. Therefore, in the present study, the physicochemical and antioxidant properties in five major kiwi fruit cultivars at three different stages of fruit harvesting were investigated.

\section{MATERIAL AND METHODS}

\section{Material}

Samples of kiwifruit (Actinidia deliciosa) cultivars, viz. 'Abbot', 'Allison', 'Bruno', 'Monty' and 'Hayward' were harvested on $1^{\text {st }}$ October, $1^{\text {st }}$ November and $1^{\text {st }}$ December 2012 from the NBPGR regional station, Bhawali, Uttarakhand (mean temperature: $2-30^{\circ} \mathrm{C}$, mean sea elevation: $60 \mathrm{~m}$, annual rain fall: $1,200-1,300 \mathrm{~mm}$, longitude: $51^{0} 09^{\prime}$ and latitude: $\left.36^{0} 43^{\prime}\right)$. Samples were brought to the laboratory under cold condition (near $0^{0} \mathrm{C}$ ). The cultivation conditions were same for all the fruits. All fruit samples were washed in cold water, peeled, sliced and stored for further analysis.

\section{Chemicals and Reagents}

Tannic acid, catechins, 1,1-diphenyl-2-picrylhydrazl (DPPH ), 2,2-azobis-3-ethylbenzthiazoline -6-sulphonic acid (ABTS), 6-hydroxy-2,5,7,8tetramethylchroman-2-carboxylic acid (Trolox), 2, 4, 6- tripyridyl-s-triazine (TPTZ), ammonium persulfate (APS) were obtained from Sigma Chemical Co. (St. Louis, MO, USA) and all other chemicals and reagents were procured from Merck, India, Ltd. All the reagents were of analytical grade and double-distilled water was used throughout the analysis.

\section{Determination of soluble solids content (SSC), titratable acidity (TAD), and pH}

Ten grams of frozen fruit tissue were homogenized in pre-chilled $40 \mathrm{~mL}$ of double distilled water. The homogenate was centrifuged at $10,000 \times \mathrm{g}$ for 15 $\min$ at $4^{0} \mathrm{C}$. Soluble solids content (SSC), was measured by adding four drops of clarified extract onto a digital refrectometer calibrated in ${ }^{\circ}$ Brix (grams of sucrose equivalent per $100 \mathrm{~g}$ of juice), and expressed as a percentage. Titratable acidity (TAD) and $\mathrm{pH}$ were determined using an automated titrimeter. Ten milliliter of clarified kiwifruit extracts were placed into a sample cup and titrated to the endpoint of $\mathrm{pH} 8.1$ using $0.1 \mathrm{~N}$ sodium hydroxide. The results were expressed as $\%$ citric acid equivalent. SSC/TAD ratio was calculated by dividing the soluble solid content values by the titratable acidity values for each cultivar.

\section{Determination of total polyphenols (TP)}

Fresh edible part of Kiwi fruit pulp $(5 \pm 0.2 \mathrm{~g})$ from each cultivar were homogenized in $25 \mathrm{~mL}$ of extraction solvent (Acetone: methanol: water: acetic acid; 40: 40: 20: 1) as described by Rababah et al. (2005) with some modification. The homogenate was transferred into a $50 \mathrm{~mL}$ centrifuge tube and incubated at $60^{\circ} \mathrm{C}$ in a water bath for $1 \mathrm{~h}$. Samples were centrifuged at 13,000 $\times$ $\mathrm{g}$ for $15 \mathrm{~min}$ at $4^{0} \mathrm{C}$, then filtered through Whatman filter paper no 1 and diluted to a final volume of $50 \mathrm{~mL}$.

Total polyphenols (TP) content was determined spectrophotometrically by the Folin-Ciocalteu method (Singleton and Rossi 1965). Extracts (200 $\mu \mathrm{L})$ were mixed with $2.6 \mathrm{~mL}$ of double distilled 
water. A blank was prepared using double distilled water instead of a sample. Subsequently, $200 \mu \mathrm{L}$ of Folin-Ciocalteu Reagent $(0.4 \mathrm{~N})$ were mixed with the sample or blank. The reaction mixture was allowed to stand at room temperature for 6 min. and then $2.0 \mathrm{~mL}$ of $7 \% \mathrm{Na}_{2} \mathrm{CO}_{3}$ solution were added to each mixture and allowed to stand at room temperature for $90 \mathrm{~min}$. The absorbance was measured at $750 \mathrm{~nm}$. A standard curve of gallic acid (purity $\geq 98 \%$ ) was constructed (20-100 $\mathrm{mg} / \mathrm{L}$ ). Results are expressed as $\mathrm{mg}$ gallic acid equivalent (GAE) per $100 \mathrm{~g}$ fresh weight.

\section{Determination of total flavonoids (TF)}

Total flavonoids were estimated using the standard methodology of Sun et al (1998) with some modifications. To the freshly prepared extract $(0.1$ $\mathrm{mL}), 0.9 \mathrm{~mL}$ methanol, $2.5 \mathrm{~mL}$ of $1 \%$ vanillin reagent and $2.5 \mathrm{~mL}$ of $9 \mathrm{M} \mathrm{HCl}$ was added. The solution was mixed thoroughly and absorbance at $500 \mathrm{~nm}$ was recorded after $20 \mathrm{~min}$ of incubation at $30^{\circ} \mathrm{C}$. Total flavonoids content was calculated from the standard calibration curve $(10-100 \mathrm{mg} / \mathrm{L})$ based on catechins (purity $\geq 96 \%$ ) and result was expressed as $\mathrm{mg}$ catechins equivelent $/ 100 \mathrm{~g}$ fresh weight (FW).

\section{Determination of ascorbic acid (Vita C)}

Ascorbic acid was determined according to the volumetric method (Thimmaiah 1999). Ten milliliter of $4 \%$ oxalic acid was added to the standard solution of vitamin $\mathrm{C}(100 \mu \mathrm{g} / \mathrm{mL}$, purity $\geq 99 \%$ ) and the resulting solution was titrated against 2, 6-dichloroindophenol dye until a pink colour end point was obtained and the titer value was noted as $\mathrm{V}_{1}$. Again, dried methanolic extract of each sample $(500 \mathrm{mg})$ was extracted with $4 \%$ oxalic acid and volume was made to $100 \mathrm{~mL}$. The filtered extract $(5.0 \mathrm{~mL})$ was mixed with $10 \mathrm{~mL}$ of $4 \%$ oxalic acid and titrated against 2, 6dichloroindophenol dye until a pink colour end point was obtained and the titer value was noted as $\mathrm{V}_{2}$. Ascorbic acid content was calculated based on the following equation: Amount of ascorbic acid $(\mathrm{mg} / 100 \mathrm{~g}$ sample $)=\left[\left(0.5 \mathrm{mg} \times \mathrm{V}_{2} \times 100 \mathrm{~mL}\right) /\right.$ $\left(\mathrm{V}_{1} \times 15 \mathrm{~mL} \times \mathrm{Wt}\right.$. of samples $\left.)\right] \times 100$, where $\mathrm{V}_{1}$ and $V_{2}$ were the volume of the dye used to titrate vitamin $\mathrm{C}$ and sample extract, respectively. The result was expressed as $\mathrm{mg}$ ascorbic acid /100 g fresh weight $(\mathrm{FW})$ of the plant material.

\section{Extraction for antioxidant activities (AA)}

For the antioxidant activity evaluation, kiwifruit tissues were extracted by homogenizing $5.0 \mathrm{~g}$ of frozen fruit $(5 \pm 0.2 \mathrm{~g})$ in $25 \mathrm{~mL}$ of $80 \%$ ethanol. Samples were transferred into $50 \mathrm{~mL}$ centrifuge tubes and sonicated for $3 \mathrm{~min}$ to obtain a uniform consistent sample. Sonicated samples were centrifuged at $12,000 \times \mathrm{g}$ for $15 \mathrm{~min}$ at $4^{0} \mathrm{C}$, filtered through Whatman No1 filter paper and diluted to a final volume of $50 \mathrm{~mL}$. All the assays were carried out in triplicate and the results were expressed as mean values \pm standard deviations.

\section{Determination of scavenging effects on DPPH radicals}

The DPPH assay was done by measuring the decrease in absorbance of methanolic DPPH solution at $515 \mathrm{~nm}$ in the presence of the extract (Brand-Williams et al. 2005) with some modifications. The stock solution was prepared by dissolving $24 \mathrm{mg}$ DPPH with $100 \mathrm{~mL}$ methanol and then stored at $-20^{\circ} \mathrm{C}$ until further use. The working solution was obtained by mixing $10 \mathrm{~mL}$ stock solution with $45 \mathrm{~mL}$ methanol to get an absorbance of $1.17 \pm 0.02$ units at $515 \mathrm{~nm}$. Fruit extracts $(150 \mu \mathrm{L})$ of different cultivar were allowed to react with $2850 \mu \mathrm{L}$ of the $\mathrm{DPPH}$ solution for $24 \mathrm{~h}$ in the dark and absorbance was taken at $515 \mathrm{~nm}$. Butylated hydroxytoluene (BHT) was employed as a reference and the radical scavenging activity was calculated as a percentage of DPPH discoloration using the equation:

$\mathrm{DPPH}$ radical scavenging $(\%)=\left[\left(\mathrm{A}_{\text {control }}-\right.\right.$ $\left.\mathrm{A}_{\text {sample }} / / \mathrm{A}_{\text {control }}\right] \times 100$

Where $A_{\text {sample }}$ is the absorbance of the solution when the extract/reference has been added at a particular level, and $\mathrm{A}_{\text {control }}$ is the absorbance of the DPPH solution without addition of extract.

\section{Determination of scavenging effect on ABTS radicals}

The ABTS assay was done by measuring the decrease in absorbance of methanolic ABTS solution at $745 \mathrm{~nm}$ in the presence of the extract (Arnao et al. 2001). The stock solutions included $7.0 \mathrm{mM}$ ABTS solution and $2.3 \mathrm{mM}$ ammonium persulfate solution. The working solution was prepared by mixing the two stock solutions in equal quantities and allowing them to react for 12 $\mathrm{h}$ at room temperature in the dark. The solution was diluted by mixing $1.0 \mathrm{~mL}$ ABTS solution with 
$3.0 \mathrm{~mL}$ methanol to obtain an absorbance of $0.9 \pm$ 0.02 units at 745 . Fruit extracts $(200 \mu \mathrm{L})$ of different cultivars were allowed to react with 2000 $\mu \mathrm{L}$ of the ABTS solution for $30 \mathrm{~min}$ in dark condition and absorbance was taken at $745 \mathrm{~nm}$. BHT was employed as a reference and the percentage inhibition was calculated using the equation:

ABTS radical scavenging $(\%)=\left[\left(\mathrm{A}_{\text {control }}-\right.\right.$ $\left.\left.\mathrm{A}_{\text {sample }}\right) / \mathrm{A}_{\text {control }}\right] \times 100$

Where $\mathrm{A}_{\text {sample }}$ is the absorbance of the solution when the extract/reference has been added at a particular level, and $\mathrm{A}_{\text {control }}$ is the absorbance of the ABTS solution without extract.

\section{Determination of ferric reducing antioxidant power (FRAP)}

The FRAP assay was done according to standard methodology of Benzie and Strain (1996) with some modifications. The stock solutions included $300 \mathrm{mM}$ acetate buffer of $\mathrm{pH} 3.6,10 \mathrm{mM}$ TPTZ (2, 4, 6- tripyridyl-s-triazine) solution in $40 \mathrm{mM}$ $\mathrm{HCl}$, and $20 \mathrm{mM} \mathrm{FeCl} \cdot 6 \mathrm{H}_{2} \mathrm{O}$ solution. The fresh working solution was prepared by mixing $25 \mathrm{~mL}$ acetate buffer, $2.5 \mathrm{~mL}$ TPTZ solution, and $2.5 \mathrm{~mL}$ $\mathrm{FeCl}_{3} \cdot 6 \mathrm{H}_{2} \mathrm{O}$ solution and solution was warmed at $37^{0} \mathrm{C}$ at the time of use. Fruit extracts $(150 \mu \mathrm{L})$ were allowed to react with $2,850 \mu \mathrm{L}$ of the FRAP solution for $30 \mathrm{~min}$ in the dark condition. Absorbance of the colored product (ferrous tripyridyltriazine complex) was taken at $593 \mathrm{~nm}$. The FRAP value was determined by plotting a standard curve $(10-100 \mu \mathrm{M})$ produced by the addition of Trolox (Merck, Darmstadt, Germany) to the FRAP reagent and was expressed as equivalents of trolox ( $\mu \mathrm{M}$ Trolox/g FW).

\section{Determination of total antioxidant activity}

The total antioxidant activity of the methanolic extract of both the sample was measured spectrophotometrically using a phosphomolybdenum method (Prieto et al. 1999), based on the reduction of Mo (VI) to Mo (V) by the sample analyte and the subsequent formation of specific green phosphate / Mo (V) compounds. Fruit extracts $(0.3 \mathrm{~mL})$ were combined with 2.7 $\mathrm{mL}$ of the reagent solution $(0.6 \mathrm{M}$ sulfuric acid, 28 $\mathrm{mM}$ sodium phosphate and $4 \mathrm{mM}$ ammonium molybdate). The sample was capped and incubated in a boiling water bath at $95^{\circ} \mathrm{C}$ for $90 \mathrm{~min}$. Samples were allowed to cool at room temperature and absorbance was measured at $695 \mathrm{~nm}$. A standard curve of trolox (10-100 $\mu \mathrm{m})$ was prepared and total antioxidant activity was expressed as equivalents of trolox ( $\mu \mathrm{m}$ Trolox/g FW).

\section{Reducing power assay}

The reducing power was determined according to the method of Huda-Faujan et al. (2009). Kiwi extracts $(200 \mu \mathrm{L})$ were taken and volume was made up to $1.0 \mathrm{~mL}$ by adding distilled water. 2.5 $\mathrm{mL}$ of $(0.2 \mathrm{M})$ sodium phosphate buffer ( $\mathrm{pH}$ 6.6) and $2.5 \mathrm{~mL}$ of $1 \%$ potassium ferricyanide were added to solution. The mixture was incubated at $50^{\circ} \mathrm{C}$ for $20 \mathrm{~min}$ and $2.5 \mathrm{~mL}$ of $10 \%$ trichloroacetic acid (w/v) was added to mixture and it was centrifuged at $3000 \times \mathrm{g}$ for $10 \mathrm{~min}$. The upper layer $(2.5 \mathrm{~mL})$ was mixed with $2.5 \mathrm{~mL}$ deionized water and $0.5 \mathrm{~mL}$ of $0.1 \%$ of ferric chloride. The absorbance was measured at $700 \mathrm{~nm}$. Higher absorbance indicates higher reducing power. Butylated hydroxytoluene (BHT) was used as a reference for comparison.

\section{Statistical analysis}

The statistical analyses were performed using the statistical package SPSS (Statistical Package for Social Science, SPSS Inc., Chicago, IL). Analyses of variance were performed by the ANOVA procedure and significance of each group was verified with one-way analysis of variance followed by Duncan's multiple range test $(\mathrm{P}<$ 0.05). For multifactorial comparison, principal component analyses (PCA) and agglomerative hierarchical clustering (AHC) were used to display the correlation between the various parameters and their relationship with the different kiwi fruit cultivars. Varimax rotation was performed to produce orthogonal transformations to the reduced factors to identify the high and low correlations better. Multifactorial analysis was carried out using the XLStat-Pro 7.5 (Addinsoft, New York, USA).

\section{RESULTS AND DISCUSSION}

Five kiwifruit cultivars were categorized according to their physicochemical properties (Table 1). $\mathrm{pH}$ values of the five cultivars were found quantitatively different. 'Abbot' had the highest $\mathrm{pH}$ values (3.20 and 3.87) harvested in the month of October and November while 'Monty' showed highest $\mathrm{pH}$ values (4.58) harvested in the month of 
December. Lowest $\mathrm{pH}$ values were recorded for 'Bruno' in the month of November (3.25) and December (4.21) (Table 1). $\mathrm{pH}$ of fruit pulp of all the cultivars was lower at the start of fruit development and significantly increased as fruit matured.

Titrated acidity (TAD) varied significantly among most of the cultivars (Table 1). TAD in all the cultivars was higher at the start of fruit development, but it decreased as the fruit matured. In the month of October and November, 'Bruno' contained the highest $\mathrm{TAD}, 0.70$ and 0.66 , respectively, while in the month of December the highest TAD was shown by Allison (0.49). 'Abbot' contained the lowest TAD in the month of October (0.51) and November (0.41) among all the cultivars. These results indicated that 'Bruno' had a more acidic flavor than the other cultivars. $\mathrm{pH}$ and $\mathrm{TAD}$ are known to contribute significantly to desirable consumer perception (Ming-Wei Sherry Kao 2006).

Soluble solids content (SSC) ranged from 8.34 (Bruno of October month) to $14.89 \%$ (Abbot of December month) (Table 1). Abbot had the highest SSC content in the month of November $(13.17 \%)$ and December (14.89\%), followed by 'Monty' in same months, while lowest was recorded for 'Bruno' for all the harvested months. These results showed that the more acidic flavor cultivars had a less sweet flavor, which was in agreement with earlier report (Mansour and Jila, 2010). SSC/TAD ratio ranged from 11.91 to 36.33 (Table 1). 'Abbot' had the highest SSC/TAD ratio followed by 'Monty' of the December month harvest, which indicated more desirable flavor.

Table 1 - Physicochemical properties of five kiwifruit cultivars measured at 3 different fruit harvesting Months.

\begin{tabular}{llllllllllllll}
\hline Cultivar & \multicolumn{3}{c}{ pH } & \multicolumn{4}{c}{ TAD } \\
\cline { 2 - 14 } Abbot & Oct & Nov & Dec & Oct & Nov & Dec & Oct & Nov & Dec & Oct & Nov & Dec \\
\cline { 2 - 13 } & $3.20^{\mathrm{a}}$ & $3.87^{\mathrm{a}}$ & $4.45^{\mathrm{a}}$ & $0.51^{\mathrm{c}}$ & $0.41^{\mathrm{c}}$ & $0.41^{\mathrm{bc}}$ & $10.53^{\mathrm{a}}$ & $13.17^{\mathrm{a}}$ & $14.89^{\mathrm{a}}$ & $20.52^{\mathrm{a}}$ & $32.63^{\mathrm{a}}$ & $36.33^{\mathrm{a}}$ \\
Bruno & $2.88^{\mathrm{a}}$ & $3.25^{\mathrm{d}}$ & $4.21^{\mathrm{a}}$ & $0.70^{\mathrm{a}}$ & $0.66^{\mathrm{a}}$ & $0.44^{\mathrm{ab}}$ & $8.34^{\mathrm{c}}$ & $9.80^{\mathrm{d}}$ & $11.17^{\mathrm{c}}$ & $11.91^{\mathrm{d}}$ & $14.94^{\mathrm{c}}$ & $25.17^{\mathrm{c}}$ \\
Allison & $2.95^{\mathrm{a}}$ & $3.29^{\mathrm{d}}$ & $4.38^{\mathrm{a}}$ & $0.68^{\mathrm{a}}$ & $0.54^{\mathrm{b}}$ & $0.49^{\mathrm{a}}$ & $9.55^{\mathrm{b}}$ & $11.89^{\mathrm{b}}$ & $13.59^{\mathrm{b}}$ & $13.96^{\mathrm{c}}$ & $21.94^{\mathrm{b}}$ & $27.89^{\mathrm{bc}}$ \\
Hayward & $3.13^{\mathrm{a}}$ & $3.64^{\mathrm{c}}$ & $4.57^{\mathrm{a}}$ & $0.60^{\mathrm{b}}$ & $0.54^{\mathrm{b}}$ & $0.37^{\mathrm{c}}$ & $8.72^{\mathrm{c}}$ & $10.79^{\mathrm{c}}$ & $11.74^{\mathrm{c}}$ & $14.47^{\mathrm{c}}$ & $19.93^{\mathrm{bc}}$ & $32.06^{\mathrm{ab}}$ \\
Monty & $2.57^{\mathrm{a}}$ & $3.78^{\mathrm{b}}$ & $4.58^{\mathrm{a}}$ & $0.60^{\mathrm{b}}$ & $0.52^{\mathrm{b}}$ & $0.41^{\mathrm{bc}}$ & $10.67^{\mathrm{a}}$ & $12.67^{\mathrm{ab}}$ & $14.36^{\mathrm{ab}}$ & $17.59^{\mathrm{b}}$ & $24.48^{\mathrm{b}}$ & $35.17^{\mathrm{a}}$ \\
\hline
\end{tabular}

Different letters in the same column indicate significant difference using LSD ( $\mathrm{p} \leq 0.05)$; TAD- titratable acidity; SSC-soluble solids content. Values are the mean of three determinations.

Ascorbic acid content showed a continuous significant decrease quantitatively with the maturity of the fruit from October to December. During October harvest, its content ranged from 96.53 (Bruno) to 77.56 (Monty) mg $100 \mathrm{~g}-1$ fresh weight (Table 2). The 'Bruno' cultivars had the highest ascorbic acid content in all the three harvests, which confirmed the findings of Mahboube et al. (2010). The lowest ascorbic acid content was recorded in cultivar 'Monty' in all the three months harvest. The results on the decrease in the ascorbic acid content with maturity of the fruits were similar to many earlier published results (Sahari et al. 2004; Tavarani et al. 2008). In present study, total phenolic content was significantly higher at the start of fruit development, but decreased as the fruit matured, which confirmed the findings of Hui-Na CHOU et al. (2008). Total phenolic contents of 'Abbot' was $2.15,1.57$ and $0.84 \mathrm{mg}$ GAE/gram FW in the month of October, November and December harvests, respectively. In month of December, 'Abbot' showed highest decrease in polyphenolic content as compared to the other cultivars.

Table 2 - Total phenolis (TP), Total flavonoids (TF) and Vitamin C concentrations of five kiwifruit cultivars measured at 3 different fruit harvesting Months.

\begin{tabular}{lccccccccc}
\hline $\begin{array}{c}\text { Cultivar } \\
\text { name }\end{array}$ & \multicolumn{3}{c}{$\begin{array}{c}\text { Total phenols } \\
\text { (mg GAE/gram FW) }\end{array}$} & \multicolumn{2}{c}{$\begin{array}{c}\text { Total flavonoids } \\
\text { (mg CE/100g FW) }\end{array}$} & \multicolumn{3}{c}{$\begin{array}{c}\text { Vitamin C } \\
\text { (mg/100 gram) }\end{array}$} \\
\cline { 2 - 10 } & Oct & Nov & Dec & Oct & Nov & Dec & Oct & Nov & Dec \\
Abbot & $2.15^{\mathrm{a}}$ & $1.57^{\mathrm{b}}$ & $0.84^{\mathrm{d}}$ & $23.45^{\mathrm{b}}$ & $26.75^{\mathrm{b}}$ & $32.54^{\mathrm{b}}$ & $80.65^{\mathrm{b}}$ & $71.34^{\mathrm{bc}}$ & $61.79^{\mathrm{c}}$ \\
Bruno & $1.70^{\mathrm{c}}$ & $1.16^{\mathrm{c}}$ & $0.99^{\mathrm{d}}$ & $18.67^{\mathrm{c}}$ & $21.14^{\mathrm{c}}$ & $22.89^{\mathrm{c}}$ & $96.53^{\mathrm{a}}$ & $87.56^{\mathrm{a}}$ & $80.49^{\mathrm{a}}$ \\
Allison & $2.02^{\mathrm{ab}}$ & $1.81^{\mathrm{a}}$ & $1.78^{\mathrm{a}}$ & $39.68^{\mathrm{a}}$ & $43.67^{\mathrm{a}}$ & $51.12^{\mathrm{a}}$ & $84.49^{\mathrm{b}}$ & $79.76^{\mathrm{abc}}$ & $75.43^{\mathrm{ab}}$ \\
Hayward & $1.64^{\mathrm{c}}$ & $1.34^{\mathrm{c}}$ & $1.15^{\mathrm{c}}$ & $19.87^{\mathrm{c}}$ & $21.78^{\mathrm{c}}$ & $25.78^{\mathrm{c}}$ & $87.54^{\mathrm{ab}}$ & $81.43^{\mathrm{ab}}$ & $72.89^{\mathrm{ab}}$ \\
Monty & $1.79^{\mathrm{bc}}$ & $1.61^{\mathrm{b}}$ & $1.51^{\mathrm{b}}$ & $11.08^{\mathrm{d}}$ & $11.35^{\mathrm{d}}$ & $12.34^{\mathrm{d}}$ & $77.56^{\mathrm{b}}$ & $70.32^{\mathrm{c}}$ & $68.56^{\mathrm{bc}}$ \\
\hline
\end{tabular}


Different letters in the same column indicate significant difference using LSD ( $p \leq 0.05$ ); GAE-gallic acid equivalence, CEcatechins equivalence, FW-fresh weight. Values are the mean of three determinations

'Hayward' showed lowest content of polyphenols as compared to other cultivars in the month of October and November (Table 2). The kiwifruit had significantly lower total flavonoids content at the start of fruit development, which increased as the fruit matured. 'Allison' contained the highest total flavonoids during all the three months (Table 2) while the lowest was recorded in 'Monty' in all the three months. At full maturity in December month, total flavonoids varied from 51.12 to 12.34 $\mathrm{mg} \mathrm{CE} / 100 \mathrm{~g} \mathrm{FW}$. The range of phenolics and total flavonoids was in agreement with the previous study (Ming-Wei Sherry Kao 2006).

Free radical scavenging activities were measured via the ABTS and DPPH radical scavenging assays (Fig. 1). The kiwifruit had significantly higher radical scavenging activities at the start of fruit development, but it decreased as the fruit matured. Both assays showed similar trends in all the cultivar. 'Allison' had the highest free radical scavenging activities for all the three months harvest, followed by 'Abbot' for the month of October, 'Bruno' for the month of November, and 'Hayward' for the month of December (Fig. 1), which was in accordance with the finding of Ming-Wei Sherry Kao (2006). The DPPH radical scavenging ranged from 16.02 (Monty, December) to $64.63 \%$ (Allison, October), while ABTS radical scavenging inhibition ranged from 16.75 (Bruno, December) to $66.35 \%$ (Bruno, October) inhibition. Vitamin C (ascorbate) and polyphenols contribute a large portion of the free radical scavenging activities because these are the most effective antioxidants in the fruits and vegetables (Pal et al. 2013). The ABTS radical method is an excellent tool for determining the ability of antioxidants to quench free radicals both in aqueous and organic phase (Kim et al. 2002; Leong and Shi 2002). High free radical quenching activities associated with DPPH radicals indicated that the antioxidants were more lipids soluble and had preference toward the lipid peroxyl radicals.

Ferric reducing antioxidant power (FRAP) assay and total antioxidant activity was carried out for all the five tested kiwi fruit cultivars during three months of fruit harvesting. Results showed that 'Allison' showed highest (353.33 $\mu \mathrm{M}$ Trolox/g FW), while 'Monty' showed lowest (97.80 $\mu \mathrm{M}$ Trolox/g FW) ferric reducing antioxidant power for the month of October. In November, maximum FRAP activity was showed by 'Bruno', followed by 'Allison' and minimum by 'Monty' (Fig. 2). In the month of December; 'Allison', 'Hayward' and 'Monty' were at par with each other. Total antioxidant activity was recorded highest in cultivar 'Allison' in all the studied months, followed by 'Monty' in October and December. In November, 'Abbot', 'Bruno' and 'Hayward' were at par with each other. The total antioxidant activity ranged from 250.49 (Monty, December) to 585.71 (Allison, October) $\mu \mathrm{M}$ Trolox/g FW.

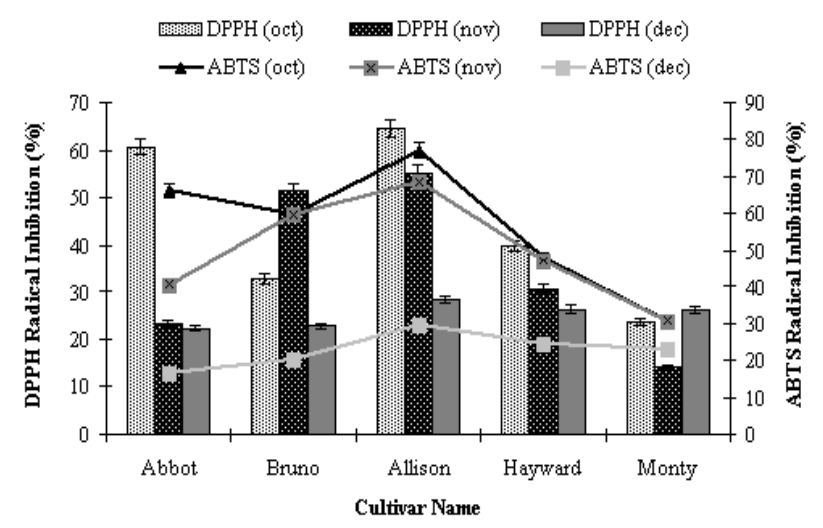

Figure 1 - Scavenging effect of kiwi fruit cultivars on DPPH and ABTS free radicals during October, November and December months. Each value is expressed as mean \pm standard error $(n=3)$.

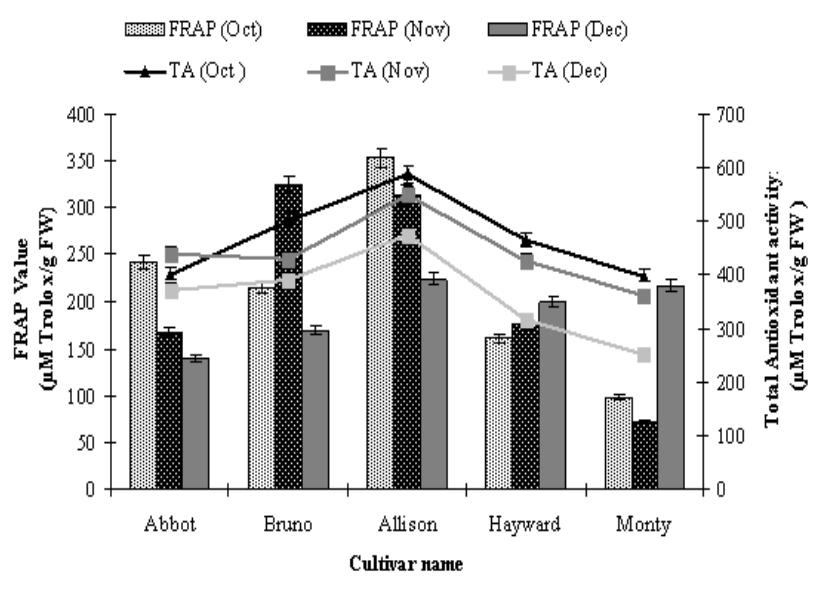

Figure 2 - FRAP value and total antioxidant activity of kiwi fruit cultivars on DPPH and ABTS free radicals during October, November and December months. Each value is expressed as mean \pm standard error $(n=3)$. 
Total antioxidant activity is highly correlated with total polyphenol content. Various antioxidative metabolites might react with free radicals, particularly peroxy radicals, which are the major propagators of the fat autoxidation chain (Rangkadilok et al. 2007). The antioxidant capacity of natural antioxidants is due to the termination of the free radical chain reaction (Shimada et al. 1992). The greater number of hydroxyl groups in polyphenol could increase the antioxidant activity of the plant material containing higher amount of these secondary metabolites (Rangkadilok et al. 2007).

Reducing power serves as a significant indicator of potential antioxidant. Three different fruit harvesting months were used to evaluate the reducing power of five different cultivars of kiwi fruit. Results showed that kiwifruits had significantly lower reducing power at the start of fruit development, but this increased as the fruits matured (Fig. 3). Cultivar 'Allison' showed highest reducing power in all the harvested months while 'Abbot' showed lowest reducing power $(0.175)$ in December harvest. In October, $(0.61)$ and in November (0.82) lowest reducing power were recorded in cultivar 'Monty'. Similar observations of antioxidant properties in terms of reducing power activity have been reported for kiwi fruit by Bekhradnia et al. (2011). It was reported that reducing power activities are associated with the presence of reducing agents, which showed antioxidant action by donating a hydrogen atom and breaking the free radical chain (Mathew and Abraham 2006).

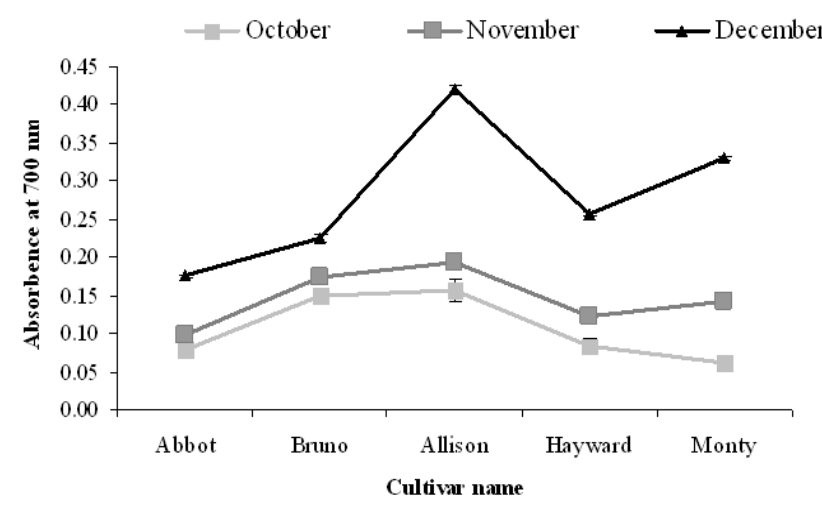

Figure 3 - Reducing power of kiwi fruit cultivars during October, November and December month. Each value is expressed as mean \pm standard error $(n=3)$.
Principal Component Analysis (PCA) is a useful statistical technique, which has found application to find out interrelationships between the different variables (Mishra et al. 2013). Multifactorial comparisons using principal component analysis clearly indicated correlation between various antioxidant parameters and their relationship in different kiwi fruit cultivars. The principal component analysis (PCA) and their correlation are shown in Figure 4A. among the data, first factor F1 represented $40.32 \%$ of variability, while the second factor F2 represented $38.14 \%$ of variability. Almost all the parameters were occupied on the upper side of the biplot, and among the parameters, the TP- (Total Polyphenols), ABTS- $\left(\mathrm{ABTS}^{\circ+}\right)$ radical scavenging activity (Oct-October, Nov-November, DecDecember), FRAP (Oct-October, Nov-November, Dec- December), $D P P H-\quad \mathrm{DPPH}^{\circ}$ radical scavenging activity (Oct-October, Nov-November, Dec- December), $T F$ - Total Flavonoids, $R P$ Reducing power (Oct-October, Nov-November, Dec- December), Vit $C$ - (Vitamin C) and TA- Total Antioxidant (Oct-October, Nov-November, DecDecember) was found occupied at left upper side of biplot. This suggested that vitamin $\mathrm{C}$ and total antioxidant activity had positive correlation, while ABTS and FRAP showed higher positive correlation. Also, total polyphenols, vitamin C, ABTS and DPPH showed positive correlation with one another. Physiochemical parameters such as $\mathrm{pH}, \mathrm{SSC}, \mathrm{SSC} / \mathrm{TAD}$ showed negative correlations with Vit $\mathrm{C}$ and FRAP Value. The 'Allison', 'Bruno' and 'Hayward' were observed at right side of biplot, showing high positive loadings to F1, while 'Abbot' and 'Monty' were observed at left side of biplot, showing high negative loadings to F2.

The interpretation of the PCA results could be explained by the positioning of the kiwi fruit cultivars and antioxidant related parameters by superimposition of respective PCA plots (Fig. 4A and Fig. 4B). Superimposition showed that 'Allison' possessed higher ABTS radical scavenging activity, DPPH radical scavenging activity, FRAP, total flavonoids, reducing power while 'Abbot' was superior in containing $\mathrm{pH}, \mathrm{SSC}$, $\mathrm{SSC} / \mathrm{TAD}$.

In order to see the patterns of clustering between the kiwi cultivars, AHC analysis was used. Using a similarity level, five kiwi cultivars were classified into mainly two clusters (Fig. 5). From $\mathrm{AHC}$ an important conclusion was drawn that on 
the basis of the variables introduced in the present analysis, cluster 1 consisted of 'Bruno' and 'Allison' and cluster 2 comprised of 'Abbot', 'Hayward' and 'Monty'. All the studied important traits could be used in the breeding programs to increase the variability for different physiochemical and antioxidative characteristics and to make suitable selections that could be acceptable to the consumers.

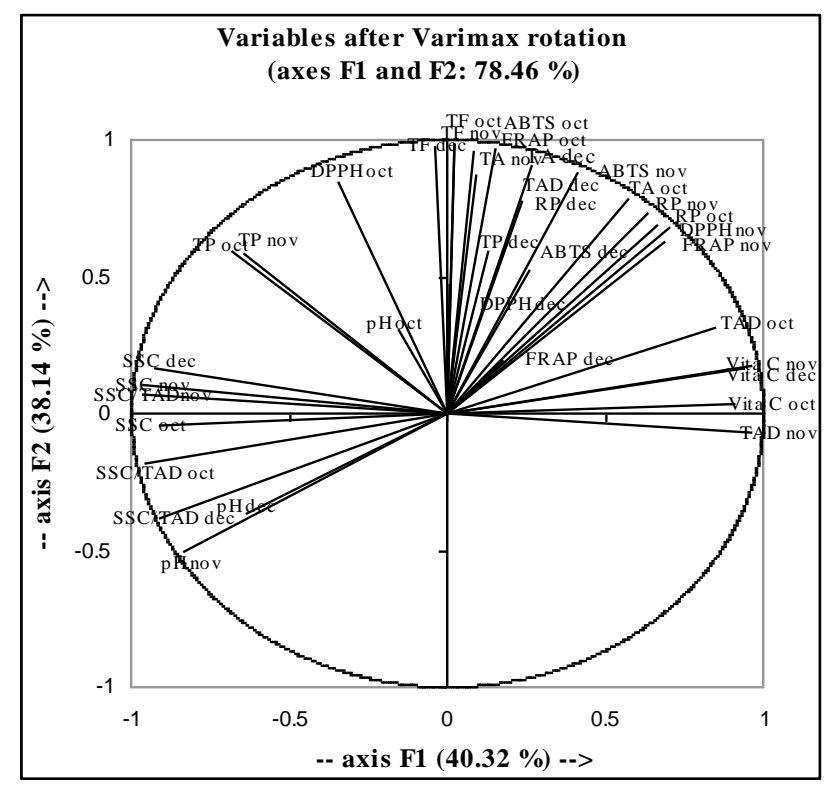

(a)

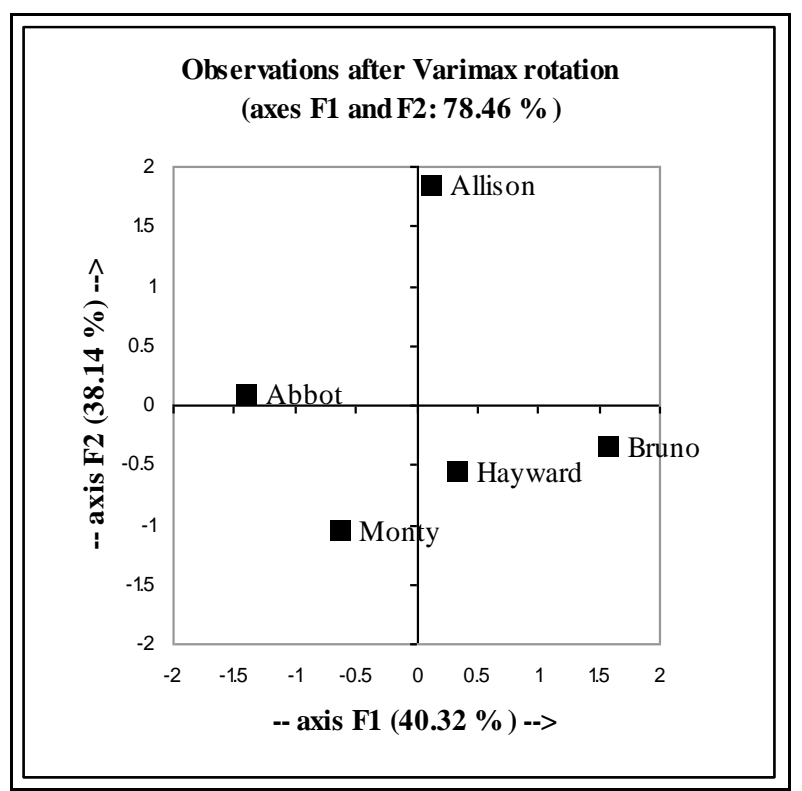

(b)

Figure 4 - (a) Multifactorial comparison and correlation matrix of physiochemical and antioxidant parameters obtained from kiwi fruit cultivars using Principal component analysis (PCA). Parameter codes: TP- Total Polyphenols, ABTS- $\mathrm{ABTS}^{\cdot+}$ radical scavenging activity (Oct-October, Nov-November, Dec- December), FRAP- (Oct-October, NovNovember, Dec- December), $D P P H$ - DPPH radical scavenging activity (Oct-October, Nov-November, Dec- December), $T F$ - Total Flavonoids, $R P$ - Reducing power (OctOctober, Nov-November, Dec- December), TA- Total Antioxidant (Oct-October, NovNovember, Dec- December), Vita $C$ - Vitamin C, SSC-soluble solids content, TAD titratable acidity and $\mathrm{pH}$ (b) Multifactorial comparison of five kiwi fruit cultivars using principal component analysis (PCA).

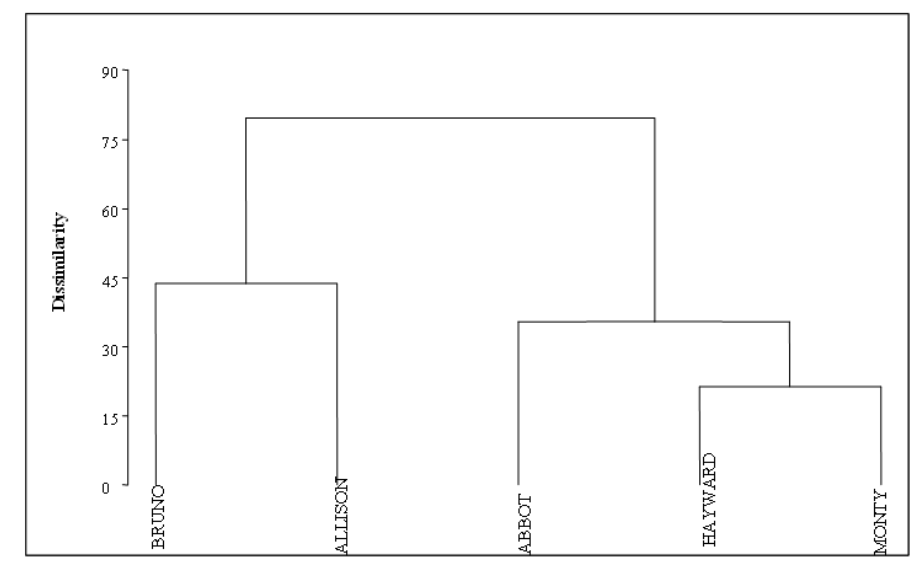

Figure 5 - Cluster analysis: Dendrogram from agglomerative hierarchical clustering (AHC) between five Kiwi fruit cultivars. 
On the basis of above results, it could be concluded that the antioxidant activity of different kiwi cultivars was dependent on the stage of fruit harvesting. In terms of antioxidant capacity and phenolic compounds, 'Allison' was having highest polyphenolic compounds and free radical scavenging activities, while 'Abbot' was, superior in containing acidity, SSC, SSC/ TAD. October month harvested fruits showed higher antioxidant activities in most of the cases. Positive correlation between higher antioxidant activity and larger amount of total phenolics was found in most of the cases. Though other antioxidants were probably present in these crops, the phenolic compounds and vitamin $\mathrm{C}$ could make a significant contribution to the antioxidant activities. Further studies on chemical characterization of antioxidative components, which may have pharmacological or dietetic applications, may yield some more information regarding certain phytochemicals present in kiwi fruit in future.

\section{ACKNOWLEDGEMENTS}

Authors acknowledge the officer in-charge of NBPGR (ICAR), regional station Bhawali, Nainital for providing the samples and all kind of support.

\section{REFERENCES}

Arnao MB, Cano A, Acosta M. The hydrophilic and lipophilic contribution to total antioxidant activity. Food Chem. 2001; 73:239-244.

Atkinson RG, Macrae EA. Kiwifruit. In: Pua EC, Davey MR (ed) Transgenic Crops V. Springer Berlin Heiderberg 2007; 60:329-346.

Bekhradnia S, Nabavi SM, Nabavi SF, Ebrahimzadeh MA. Antioxidant activity of kiwifruit (Actinidia chinensis). Pharmacology online. 2011; 1:758-764.

Benzie I, Strain J. The ferric reducing ability of plasma (FRAP) as a measure of antioxidant power: The FRAP assay. Anal Biochem. 1996; 239:70-76.

Brand-Williams W, Cuvelier ME, Berset C. Use of free radical method to evaluate antioxidant activity. $L W T$ Food Sci Technol. 1995; 28: 25-30.

Burdon J, McLeod D, Lallu N, Gamble J, Petley M, Gunson A. Consumer evaluation of "Hayward" kiwifruit of different at-harvest dry matter contents. Postharvest Biol Technol. 2004; 34: 245-255.
Collins BH, Horska A, Hotten PM, Riddoch C, Collins AR. Kiwi fruit protects against oxidative DNA damage in human cells in vitro. Nutr Cancer. 2001; 39:148-153.

Crisosto $\mathrm{CH}$, Crisosto GM. Understanding consumer acceptance of early harvested 'Hayward' kiwifruit. Postharvest Biol Technol. 2001, 22:205-213.

Ferguson AR, Huang HW. Genetic resources of kiwifruit: domestication and breeding. Hort Rev. 2001; 33: 1-121.

Halliwell B, Whitemann M. Measuring reactive species and oxidative damage in vivo and in cell culture: how should you do it and what do the results mean? $\mathrm{Br} J$ Pharmacol. 2004; 142: 231-255.

Huda-Faujan N, Noriham A, Norrakiah AS, Babji AS. Antioxidant activity in plants methanol extract containing phenolic compounds. Afr J Biotechnol. 2009; 8:484-489.

Hui-Na C, Cheng-Chu N, Andi Shau-Mei O, Tse-Heng C, Chia-Chen C. Characterization of the physicochemical and antioxidant properties of Taiwanese kiwifruit (Actinidia setosa). Bot Stud. 2008; 49: 215224.

Kim KO, Lee KW, Lee HJ, Lee CY. Vitamin C equivalent Antioxidant capacity (VCEAC) of Phenolic Phytochemicals. J Agric Food Chem. 2002; 50: 3713-3717.

Leong LP, Shui G. An investigation of antioxidant capacity of fruits in Singapore markets. Food Chem. 2002; 76: 69-75.

Mahboube Z, Mohammad AS, Mohsen B, Hamidreza S. Physicochemical and Enzymatic Properties of Five Kiwifruit Cultivars during Cold Storage. Food Bioprocess Technol. 2010; 3: 239-246.

Mansour, AM, Jila RK. The comparison of carbohydrate and mineral changes in three cultivars of kiwifruit of Northern Iran during fruit development. Aust J Crop Sci. 2010; 4: 49-54.

Mathew SA, Braham TE. In vitro antioxidant activity and scavenging effects of Cinnamomum verum leaf extract assayed by different methodologies. Food Chem Toxicol. 2006; 44: 198-206.

Ming-Wei S, Kao A. Comparative Study of Antioxidant and Physicochemical Properties of Blackberry and Kiwifruit (Master of Science thesis) Auburn University. 2006.

Mishra KK, Pal RS, Arun KR, Chandrashekara C, Jain SK, Bhatt JC. Antioxidant properties of different edible mushroom species and increased bioconversion efficiency of Pleurotus eryngii using locally available casing materials. Food Chem. 2013; 138: 1557-1563.

Nishiyama I. Fruits of the Actinidia Genus. In: Advances in Food and nutrition Research, Taylor SL (ed) Academic Press. 2007; 52: 293-324. 
Pal RS, Arun KR, Agrawal PK, Bhatt JC. Antioxidant capacity and related phytochemicals analysis of methanolic extract of two wild edible fruits from north western Indian Himalaya. Int J Pharm Bio Sci. 2013; 4: 113-123.

Prieto P, Pineda M, Aguilar M. Spectrophotometric quantization of antioxidant capacity through the formation of a phosphomolybdenum complex: Specific application to the determination of vitamin E. Anal Biochem. 1999; 269: 337-341.

Rababah TM, Ereifej KI, Howard L. Effect of ascorbic acid and dehydration on concentrations of total phenolics, antioxidant capacity, anthocyanins, and color in fruits. J Agric Food Chem. 2005; 53: 44444447.

Rangkadilok N, Sitthimonchai S, Worasuttayangkurn L, Mahidol C, Ruchirawat M, Satayavivad J. Evaluation of free radical scavenging and antityrosinase activities of standardized longan fruit extract. Food Chem Toxicol. 2007; 45: 328-336.

Sahari MA, Boostani M, Hamidi EZ. Effect of low temperature on the ascorbic acid content and quality characteristics of frozen strawberry. Food Chem. 2004; 86: 357-363.

Sheng Y, Akesson C, Holmgren K, Bryngelsson C, Giamapa V, Pero RW. An active ingredient of Cat's Claw water extracts: Identification and efficacy of quinic acid. J Ethnopharmacol. 2005; 96: 577-584.
Shimada K, Fujikawa K, Yahara K, Nakamura T. Antioxidative properties of xanthan on the autoxidation of soybean oil in cyclodextrin emulsion. J Agric Food Chem. 1992; 40: 945-948.

Singleton VL, Rossi JA. Colorimetry of total phenolics with phosphomolybdic phosphotungstic acid reagents. Am J Enol Vitic. 1965; 16: 144-158.

Song P. Anticancer activity of Chinese kiwi fruit. Nutr Res. 1984; 6: 109-114.

Sun B, da-Silva JM, Spranger I. Critical factors of vanillin assay for Catechins and Proanthocyanidins. $J$ Agric Food Chem. 1998; 46: 4267-4274.

Tavarani S, Degl-Inocenti E, Remorini D, Massai R, Guidi L. Antioxidant capacity, ascorbic acid, total phenols and carotenoids changes during harvest and after storage of Hayward kiwifruit. Food Chem. 2008; 107: 282-288.

Thimmaiah SK. In: Standard method of Biochemical analysis, $3^{\text {rd }}$ Edn, New Delhi Kalyani Publisher: 1999 ; pp. 278.

Yang JX. Chinese pharmaceuticals for cancers. Peking: General people's health Publishers. 1981; pp 121 122. 